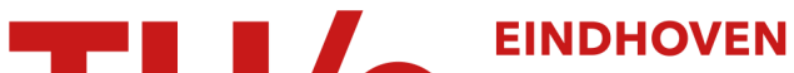 UNIVERSITY OF TECHNOLOGY
}

\section{The nucleation behavior of supercooled water vapor in helium}

Citation for published version (APA):

Peeters, P., Gielis, J. J. H., \& Dongen, van, M. E. H. (2002). The nucleation behavior of supercooled water vapor in helium. Journal of Chemical Physics, 117(12), 5647-5653. https://doi.org/10.1063/1.1501885

DOI:

10.1063/1.1501885

Document status and date:

Published: 01/01/2002

Document Version:

Publisher's PDF, also known as Version of Record (includes final page, issue and volume numbers)

Please check the document version of this publication:

- A submitted manuscript is the version of the article upon submission and before peer-review. There can be important differences between the submitted version and the official published version of record. People interested in the research are advised to contact the author for the final version of the publication, or visit the $\mathrm{DOI}$ to the publisher's website.

- The final author version and the galley proof are versions of the publication after peer review.

- The final published version features the final layout of the paper including the volume, issue and page numbers.

Link to publication

\section{General rights}

Copyright and moral rights for the publications made accessible in the public portal are retained by the authors and/or other copyright owners and it is a condition of accessing publications that users recognise and abide by the legal requirements associated with these rights.

- Users may download and print one copy of any publication from the public portal for the purpose of private study or research.

- You may not further distribute the material or use it for any profit-making activity or commercial gain

- You may freely distribute the URL identifying the publication in the public portal.

If the publication is distributed under the terms of Article $25 \mathrm{fa}$ of the Dutch Copyright Act, indicated by the "Taverne" license above, please follow below link for the End User Agreement:

www.tue.nl/taverne

Take down policy

If you believe that this document breaches copyright please contact us at:

openaccess@tue.nl

providing details and we will investigate your claim. 


\title{
The nucleation behavior of supercooled water vapor in helium
}

\author{
P. Peeters, J. J. H. Gielis, and M. E. H. van Dongen \\ Eindhoven University of Technology, Department of Applied Physics, P.O. Box 513, 5600 MB Eindhoven, \\ The Netherlands
}

(Received 9 May 2002; accepted 1 July 2002)

\begin{abstract}
The nucleation behavior of supersaturated water vapor in helium is experimentally investigated in the temperature range of 200-240 K. The experiments are performed using a pulse expansion wave tube. The experimental results show a sharp transition in the nucleation rates at $207 \mathrm{~K}$. We suggest that the transition is due to the transition of vapor/liquid to vapor/solid nucleation (ordered with decreasing temperature). A qualitative theoretical explanation is given based on the classical nucleation theory and the surface energy of ice. (C) 2002 American Institute of Physics.
\end{abstract}

[DOI: $10.1063 / 1.1501885]$

\section{INTRODUCTION}

The experimental results presented in this paper are part of an ongoing research program, focused on the nucleation behavior of natural gas. ${ }^{1}$ Apart from the main component methane, natural gas contains many other (vapor) components. These other vapor components can roughly be separated into two different categories, being water and hydrocarbons. One of the aims in the program is trying to establish whether or not nucleation of ice and/or the nucleation of methane hydrates occurs. As a first step towards this goal, the nucleation behavior of water in helium was studied. This way, hydrate formation is excluded. What remains are three possible nucleation processes. These are vapor/liquid, liquid/ solid, and vapor/solid nucleation. The nucleation behavior of water vapor (in an inert carrier gas) has been studied before, and a recent and extensive study was presented in a paper by Wölk and Strey. ${ }^{2}$ They measured nucleation rates in the temperature range of 219-260 K. In their paper only vapor/ liquid nucleation is considered, and no indications for other nucleation processes are given. Another extensive study was performed by Peters and Paikert. ${ }^{3}$ They measured nucleation rates of water in argon in the temperature range of 200-250 $\mathrm{K}$. The results presented here are in the temperature range from 200 to $235 \mathrm{~K}$. Attention will be focused on the detection of vapor/solid nucleation.

\section{NUCLEATION}

Through the years several expressions for the nucleation rate $J$ have been developed. ${ }^{1,4}$ For analyzing our experimental results we will use an expression inspired by classical nucleation theory,

$$
J=K \exp \left(-\frac{W}{k_{B} T}\right),
$$

in which $K$ is a kinetic factor, $T$ is the temperature, and $W$ is the energy needed to form a critical cluster, at isothermal and isobaric conditions. When a vapor is supersaturated, it can lower its Gibbs free energy by forming a liquid phase. However, in order to form a liquid phase, an interface between the vapor and the liquid has to be formed, which increases the energy of the system. The lowering of the free energy due to the bulk liquid formation is proportional to the volume $\left(r^{3}\right)$ of the liquid, while the increase of the free energy due to the formation of the interface is proportional to the area of this interface $\left(r^{2}\right)$. Therefore, the energy of formation of a cluster of molecules has a maximum as a function of the cluster size. The critical cluster is the cluster at this maximum and $W$ is its corresponding work of formation. For nucleation from the vapor phase classical nucleation theory gives ${ }^{5}$

$$
W=\frac{16 \pi}{3}\left(\frac{M}{N_{A} \rho k_{B} T \ln (S)}\right)^{2} \sigma^{3},
$$

and

$$
K=\left(\frac{p_{\text {sat }}}{k_{B} T}\right)^{2}\left(\frac{2 \sigma M}{\pi N_{A}}\right)^{1 / 2} \frac{S}{\rho} .
$$

The work of formation of a critical nucleus $W$ and the rate factor $K$ depend on the molar mass $M$, the specific density $\rho$ of the condensed phase, the surface tension $\sigma$ and the saturated vapor pressure $p_{\text {sat }}$. At near-atmospheric pressures the supersaturation $S$ of the vapor in a carrier gas can be expressed as ${ }^{5}$

$$
S=\frac{p_{v}}{p_{\text {sat }}}=\frac{y p}{p_{\text {sat }}},
$$

where $y$ is the vapor fraction. Expressions for the physical properties are given in the Appendix. In the original expression of the CNT an extra factor $S$ appeared in the rate factor $K$. However, this is now generally believed to be incorrect. More details are given in the book by Kashchiev. ${ }^{6}$

\section{SURFACE ENERGY OF ICE}

When will vapor/ice nucleation become more probable than vapor/liquid nucleation? In terms of the classical nucleation theory this means that the barrier height in the energy of formation $(W)$ of a critical ice nucleus becomes smaller than the barrier for the formation of a critical water nucleus. Using Eq. (2), these energies of formation can be compared when the physical properties of ice are known. The density and saturated vapor pressure of ice are readily available. $\mathrm{Ob}-$ 
taining an expression for the surface tension (or rather surface energy) of ice is less straightforward. Ice at temperatures above about $235 \mathrm{~K}$ is covered with a quasiliquid layer (QLL) of microscopic size. ${ }^{7-9}$ In this case the ice/vapor interface actually consists of two interfaces, an ice/water interface and a water/vapor interface. Therefore, for temperatures above about $235 \mathrm{~K}$ the equilibrium ice/vapor surface energy can be obtained using Antonow's rule, ${ }^{10,11}$

$$
\sigma_{\text {solid/vapor }}=\sigma_{\text {solid/liquid }}+\sigma_{\text {liquid/vapor }} .
$$

For temperatures well below $235 \mathrm{~K}$ the QLL has disappeared and the ice/vapor surface energy can be approximated using the latent heat of evaporation. ${ }^{12}$ When it is assumed that a water molecule that moves from the bulk ice to the surface loses half of its bonding energy, the surface energy of the ice/vapor interface corresponds approximately to half of the energy of evaporation. This energy of evaporation is calculated from the entropy difference between the bulk ice and the vapor,

$$
L_{\text {solid/vapor }}=T \Delta S_{\text {solid/vapor }} \text {. }
$$

We then have the surface energy per mole of ice. To obtain the surface energy per unit of area, the number of moles (of ice) per unit area is estimated from the density of ice. The molecules are assumed to occupy a spherical volume of radius

$$
r_{\text {sphere }}=\left(\frac{3 M}{4 \pi N_{A} \rho_{\text {solid }}}\right)^{1 / 3} .
$$

The square of the diameter of the sphere gives the area per molecule on the ice surface. This corresponds to

$$
a=\left(4 N_{A}\left(\frac{3 M}{4 \pi N_{A} \rho_{\text {solid }}}\right)^{2 / 3}\right)^{-1}
$$

moles of ice per unit area. Finally, we have for the surface energy of ice below approximately $235 \mathrm{~K}$ the following expression:

$$
\sigma_{\text {solid } / \text { vapor }}=\frac{1}{2} C L_{\text {solid } / \text { vapor }} a,
$$

in which $C$ is a correction factor of order 1 .

\section{EXPERIMENT}

The experimental setup has been described in detail elsewhere. ${ }^{13,14}$ The improved procedure of mixture preparation has been described in the paper by Peeters et al. ${ }^{1}$ The nucleation rates are measured using the nucleation pulse method. The method is based on the fact that the nucleation rate is a very steep function of the supersaturation. First, the gas/vapor mixture is rapidly brought into a state of high supersaturation, in which significant nucleation takes place. This is generally achieved by adiabatically expanding the mixture. Shortly after the expansion the mixture is slightly compressed, decreasing the supersaturation somewhat. In this new less supersaturated state no significant nucleation occurs, while the clusters formed during the state of high supersaturation (the nucleation pulse) can grow to optically detectable sizes. This way, the formation and the growth of

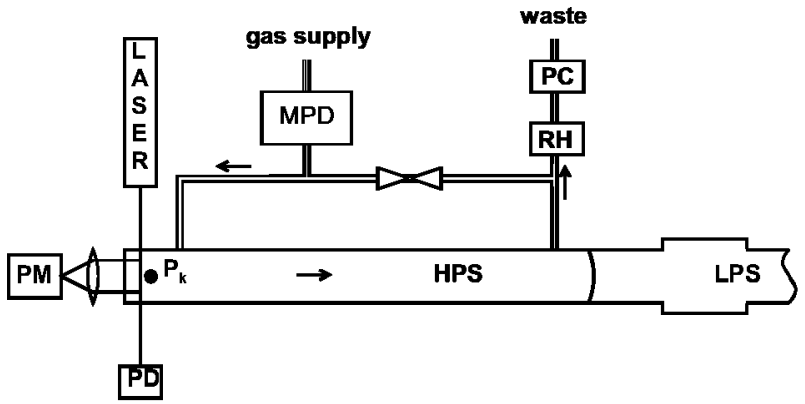

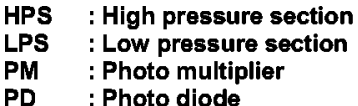

PD Photo diode

FIG. 1. Schematic view of the setup.

the droplets is effectively decoupled. The nucleation pulse can be obtained using a pulse expansion wave tube. This is basically a shock tube, the high pressure section of which is used as the test section. A schematic view of the setup is shown in Fig. 1. Just behind the diaphragm, separating the high pressure section from the low pressure section, there is a local increase in the diameter of the tube. When the diaphragm is burst, an expansion fan will travel into the high pressure section and reflect at the end wall, causing a rapid decrease of the pressure. The shock wave travelling into the low pressure section will partially reflect at the local widening. This will result in the formation of a small pressure dip at the end wall of the high pressure section, i.e., the nucleation pulse. The droplets formed in the pulse will keep growing until the shock wave, reflected from the end wall of the low pressure section, reaches the end wall of the high pressure section. The low pressure section has recently been extended from $6.42 \mathrm{~m}$ to $9.23 \mathrm{~m}$, effectively increasing the measuring time by about $40 \%$. The pressure at the end wall of the HPS is measured using a Kistler 603B dynamic pressure transducer. The temperature is calculated from the pressure assuming an adiabatic isentropic expansion. The pressure transducer was calibrated in the shock tube before as well as after the experiments. Both calibrations gave the same result, within the experimental accuracy $(<0.2 \%$ relative difference). The number density and the size of the droplets are determined using a combination of light extinction and $90^{\circ}$ light scattering (CAMS). The nucleation rate is obtained by taking the ratio of the number density and the time duration of the nucleation pulse. With this setup nucleation rates between $10^{14}$ and $10^{17} \mathrm{~m}^{-3} \mathrm{~s}^{-1}$ can be measured.

The test gas mixture originates from a combination of two different gas streams. One is a "wet" helium gas stream. This gas stream is saturated with water by bubbling it through two containers half-filled with water, at a constant pressure (5.17 bar) and temperature (291.2 K). This way the wet gas stream has a constant vapor fraction. It can be diluted by the second gas stream, which consists of dry helium only. The gas streams are controlled by mass flow controllers. The composition of the gas/vapor mixture is altered by setting different ratios of the mass flow controllers. Before the start of an experiment, the high pressure section is flushed (at the initial pressure of the experiment) with the 


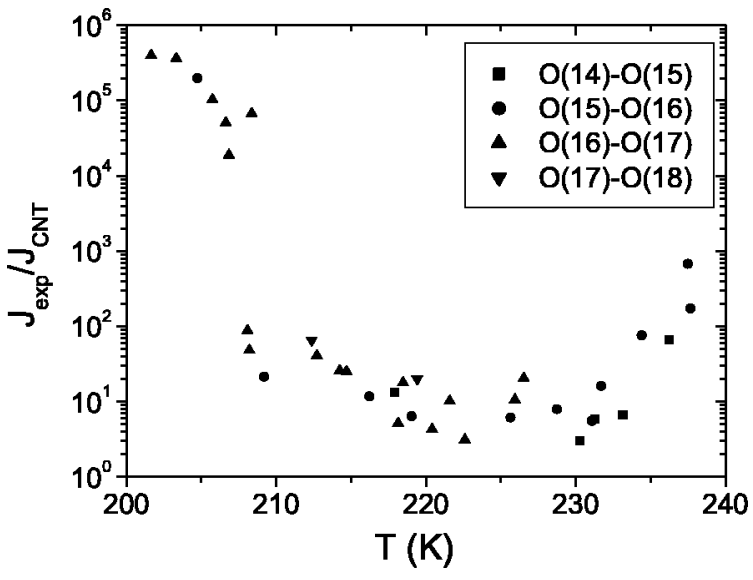

FIG. 2. Ratio of experimental nucleation rates to theoretical classical nucleation rates of liquid water, as a function of the temperature.

gas/vapor mixture. When the humidity sensor takes on a constant value, equilibrium has been reached between the walls of the setup and the gas/vapor mixture, and the experiment can begin.

\section{RESULTS AND DISCUSSION}

In Fig. 2 the results of the nucleation experiments are shown as a function of the temperature. The experimental rates are scaled with the theoretical classical nucleation rates. It is apparent that around $207 \mathrm{~K}$ there is a jump in the scaled rates of about 4 orders of magnitude. This jump is not caused by a peculiar behavior of the analytical expression for the nucleation rate. Rather, it is caused by a change in the nucleation process. This also becomes apparent when we look at the supersaturation of water as a function of the temperature, shown in Fig. 3. In order to measure nucleation rates within our experimental nucleation rate "window," (O(14)-O(18)) the supersaturation of water has to be decreased again at 207 $\mathrm{K}$. The jump in the scaled nucleation rates can be explained by the onset of vapor/ice nucleation. Onset of liquid/ice nucleation cannot explain the jump in the scaled nucleation rates. It would mean that the formed liquid droplets would freeze, rendering the same amount of measured particles

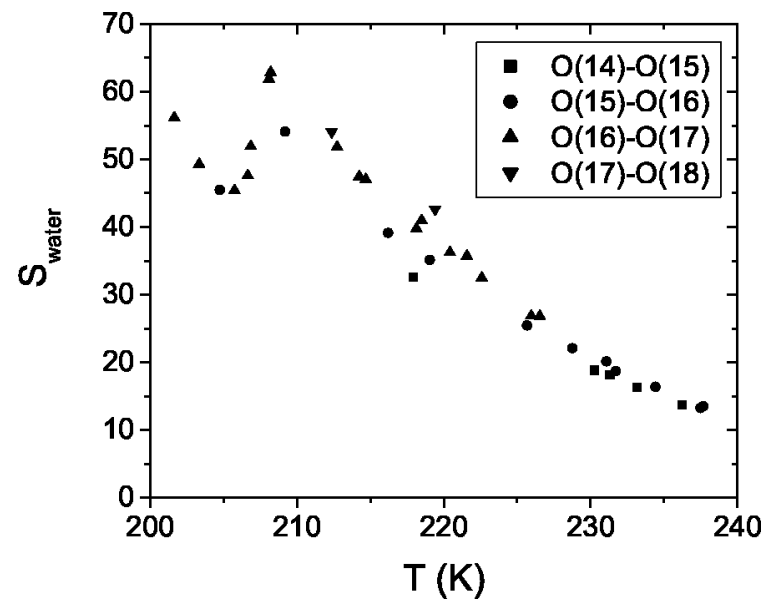

FIG. 3. Experimental supersaturation of water vapor with respect to liquid water, as a function of temperature.

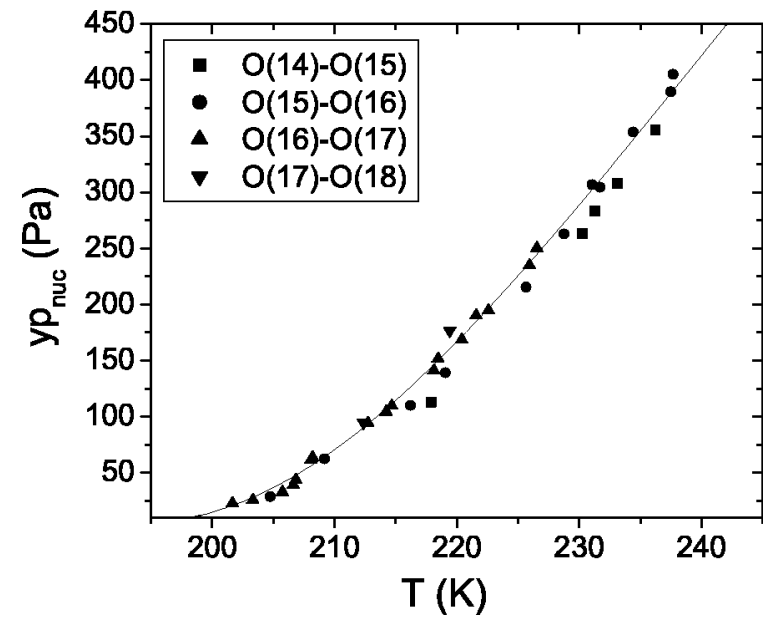

FIG. 4. Experimental partial vapor pressure vs nucleation temperatures. The line represents a fit through the data.

(droplets) per unit volume. Effectively, this gives a small error in the measured number density, since the scattering properties of (spherical) ice particles are slightly different from those of water droplets. This gives an error in the measured number density (and nucleation rates) of about $15 \%$, which is well within the experimental error of a factor 3 .

Because of the steep dependency of the nucleation rate on the supersaturation, the experimental vapor fractions form a narrow band in the $y p-T$ diagram, as shown in Fig. 4. To compare the energy of formation of a critical water nucleus to that of a critical ice nucleus for our experiments, the narrow band of experimental partial vapor pressures was approximated by the curve also shown in Fig. 4. The partial vapor pressures and the physical properties can now be put into the expression for the energy of formation for a critical nucleus [Eq. (2)]. This results in different temperature dependent curves for the energy of formation (for our experiments), which are shown in Fig. 5. When the value $C=0.6$ is taken for the correction factor in the expression for the "dry"-ice/vapor surface energy [Eq. (9)], the vapor/"dry"-

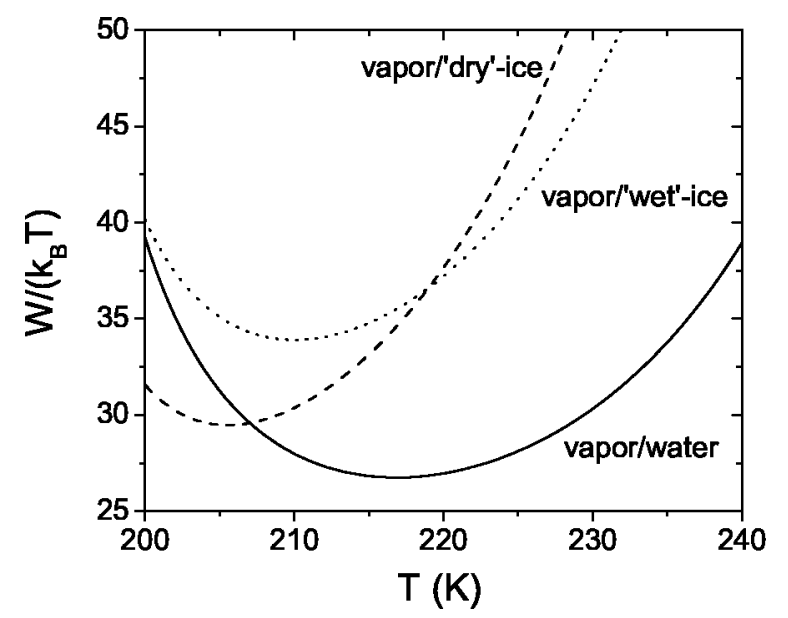

FIG. 5. The energy of formation of a critical nucleus as a function of temperature. Line: vapor/liquid nucleation. Dashed line: vapor/"dry"-ice nucleation [using Eq. (9) with $C=0.6$ ]. Dotted line: vapor/"wet" -ice nucleation [using Eq. (5)]. 


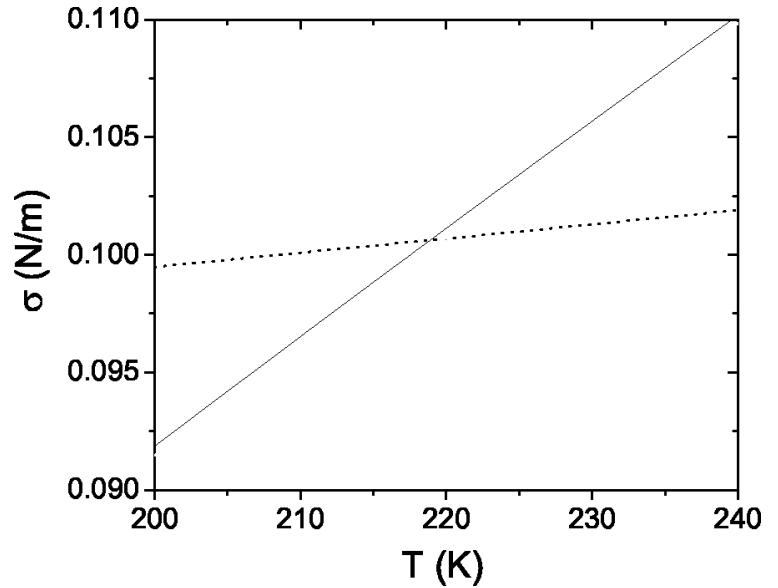

FIG. 6. Surface energy of ice as a function of temperature. Line: estimated "dry"-ice surface energy, with $C=0.6$. Dotted line: "wet"-ice surface energy, obtained using Antonow's rule.

ice curve intersects the vapor/liquid curve at $207 \mathrm{~K}$, making vapor/"dry"-ice nucleation more probable below this temperature. A transition to vapor/"wet"-ice nucleation will not occur, as the energy of formation of such a cluster is always larger than at least one of the other two. In Fig. 6 the "dry" ice and "wet"-ice approximations for the surface energy are shown in one figure. For $C=0.6$ the "dry"-ice surface energy intersects the "wet"-ice surface energy at $220 \mathrm{~K}$. This temperature is within the range of experimentally observed temperatures at which the ice surface becomes completely "dry."7-9 Above this temperature the equilibrium surface consist of an ice/liquid interface, plus a very thin liquid layer (which is not stable in bulk), and a liquid/gas interface. Below the transition temperature the surface consists of an ice/ gas interface only. The temperature derivative of the surface energy is discontinued at the transition temperature. The transition is therefore a first order phase transition of the surface. This is also known as a Cahn transition. ${ }^{11,15}$

Nucleation rates of water in argon have recently been measured by Wölk and Strey. ${ }^{2}$ They used a pulse expansion cloud chamber, with which they can measure nucleation rates between $10^{11}$ and $10^{15} \mathrm{~m}^{-3} \mathrm{~s}^{-1}$. So their upper range of nucleation rates corresponds to our lower range. Their cylindrical measuring chamber has a diameter of $3 \mathrm{~cm}$ and a total volume of about $25 \mathrm{~cm}^{3}$. The measurements were performed in the temperature range of 219-260 K. Peters and Paikert ${ }^{3}$ also measured nucleation rates of water in argon, in the temperature range of 200-245 K, using an expansion wave tube, similar to ours. The scatter in their data amounts up to several orders of magnitude, especially in the lower temperature range. In Fig. 7 our data are shown together with the data by Wölk and Strey. ${ }^{2}$ At each temperature, the data by Wölk and Strey show a range of scaled nucleation rates. The lower values of the scaled (isothermal) nucleation rates correspond to a higher supersaturation. The temperature dependency of the nucleation rates measured by Wölk and Strey differs from our measured dependency.

In order to investigate this difference we considered the possibility of the influence by thermal boundary layers in our setup. Our measuring volume is located $5 \mathrm{~mm}$ from the end

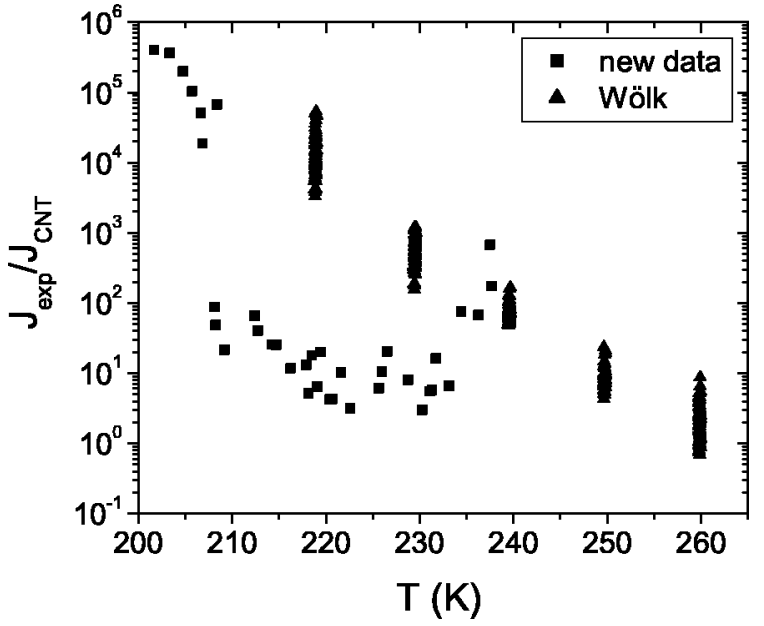

FIG. 7. Experimental nucleation rates as a function of temperature. The experimental rates are scaled with the theoretical classical nucleation theory (for vapor/liquid nucleation).

wall of the HPS. To calculate the influence of time dependent conductive heat transport from the "hot" end wall of the HPS to the cold gas the following (one-dimensional) coupled differential equations have to be solved:

$$
\frac{\partial \rho}{\partial t}+\frac{\partial \rho u}{\partial x}=0
$$

and

$$
\rho c_{p}\left(\frac{\partial T}{\partial t}+u \frac{\partial T}{\partial x}\right)=\frac{\mathrm{d} p}{\mathrm{~d} t}+\frac{\partial}{\partial x} k \frac{\partial T}{\partial x},
$$

which represent the conservation of mass and energy, respectively. Here, $u$ is the velocity, $k$ is the thermal conductivity, $t$ is the time, and $x$ is the position coordinate. Before the expansion $(t=0)$ the temperature is uniform $\left(T_{0}\right)$. The temperature at the end wall $(x=0)$ remains equal to $T_{0}$. The temperature far from the end wall $(x \rightarrow \infty)$ is equal to the time dependent isentropic temperature $T_{\infty}(t)$, which is calculated from the known uniform time dependent pressure $p(t)$. It was shown by $\mathrm{Keck}^{16}$ and Van Dongen ${ }^{17}$ that for an ideal gas the coupled differential equations can be rewritten in the form,

$$
\frac{\partial}{\partial s}\left(\frac{T}{T_{\infty}}\right)=\frac{\partial^{2}}{\partial \eta^{2}}\left(\frac{T}{T_{\infty}}\right),
$$

where the coordinate transformations,

$$
\eta(x, t)=\int_{0}^{x} \frac{\rho^{\prime}}{\rho_{0}} \mathrm{~d} x^{\prime},
$$

and

$$
s(t)=\alpha_{0} \int_{0}^{t} \frac{p^{\prime}}{p_{0}} \mathrm{~d} t^{\prime},
$$

are used. Furthermore, it is assumed that the thermal conductivity is proportional to the temperature, resulting in

$$
k=k_{0} \frac{T}{T_{0}}=\rho_{0} c_{p} \alpha_{0} \frac{T}{T_{0}},
$$




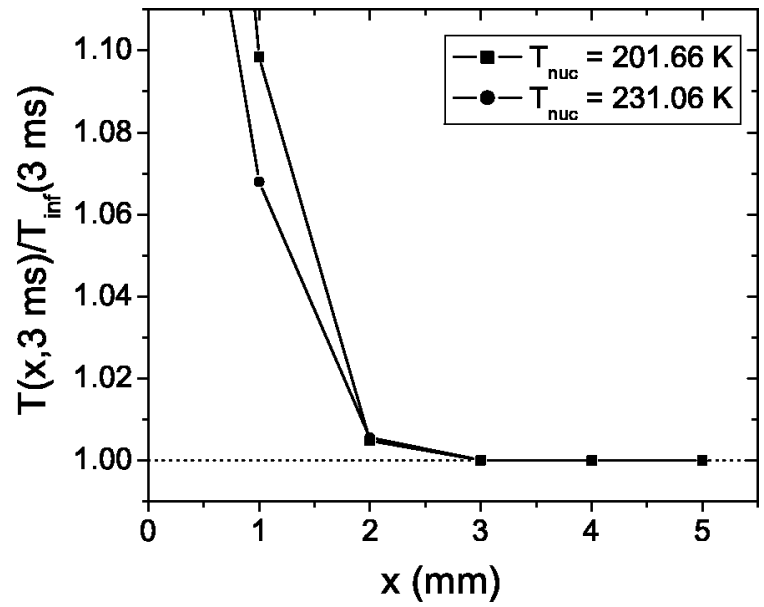

FIG. 8. Development of the thermal boundary layers at the end wall of the HPS, assuming one-dimensional unsteady heat conduction.

where $\alpha_{0}$ is the initial thermal diffusivity. For the initial condition $T(\eta, 0)=T_{\infty}(0)$, and boundary conditions $T(0, s)$ $=T_{0}$ and $T(\infty, s)=T_{\infty}(s)$ the solution of Eq. (12) is ${ }^{16}$

$$
\frac{T}{T_{\infty}}=1+\int_{0}^{t} \operatorname{erfc}\left(\frac{\eta}{2}\left(\alpha_{0} \int_{t^{\prime}}^{t} \frac{p^{\prime \prime}}{p_{0}} \mathrm{~d} t^{\prime \prime}\right)^{-1 / 2}\right) \frac{\mathrm{d}}{\mathrm{d} t^{\prime}}\left(\frac{T_{0}}{T_{\infty}^{\prime}}\right) \mathrm{d} t^{\prime} .
$$

This integral can be solved numerically using the pressure $p(t)$ obtained from the experiment. One then obtains the temperature as a function of the transformed position coordinate $\eta$ and time $t$. The actual position coordinate $x$ can easily be obtained, using

$$
x(\eta, t)=\frac{p_{0}}{p(t)} \int_{0}^{\eta T^{\prime}} \frac{T_{0}}{T_{0}} \eta^{\prime},
$$

which is the inverse of Eq. (13). The boundary layer calculations are performed for experiment numbers 482 and 500 . Experiment 482 is the one with the lowest nucleation temperature $(201.66 \mathrm{~K})$, while experiment 500 has a nucleation temperature of $231.06 \mathrm{~K}$. In Fig. 8 the temperature profile resulting from both experimental pressure signals is shown. The time corresponds to $3 \mathrm{~ms}$ after the start of the expansion. The nucleation pulse has already occurred within these $3 \mathrm{~ms}$. As can be seen from Fig. 8, there is no influence of the thermal boundary layers at the measuring position $(5 \mathrm{~mm})$ before the ending of the nucleation pulse. From this we can conclude that the thermal boundary layers do not influence the nucleation process. In Fig. 9 the temperature profile of these experiments at the measuring position $(5 \mathrm{~mm})$ is shown as a function of time, scaled with the isentropic temperatures. The thermal boundary layers reach the measuring position after about $5 \mathrm{~ms}$, measured from the end of the nucleation pulse. Therefore, the thermal boundary layers influence the droplet growth process. However, this will only give an error in the measured number density of $<1 \%$, and can certainly not explain a difference of several orders of magnitude in the measured nucleation rates.

The difference in our measurements and those of Wölk and Strey $^{2}$ could also originate from thermal influences due to the separation of viscous and thermal boundary layers

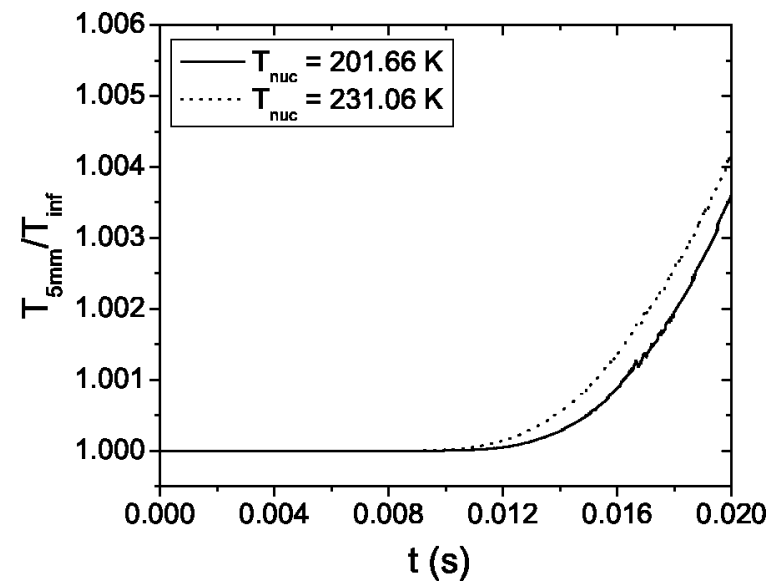

FIG. 9. Development of the thermal boundary layers as a function of time, at the measuring position ( $5 \mathrm{~mm}$ from the end wall of the HPS). The temperatures are scaled with the isentropic temperatures.

formed along the side walls of the tube, caused by the space and time dependent flows induced by the expansion. In order to investigate this, the full three-dimensional Navier-Stokes equations have to be solved. This is a subject of current investigation. Possibly, this can explain the difference in temperature dependency of the nucleation rates, measured with the different devices. However, it is highly unlikely that this can explain the jump in the nucleation rates we measured at the nucleation temperature of $207 \mathrm{~K}$. Therefore, the proposition of the onset of a different nucleation process at this temperature, being vapor/ice nucleation, remains valid.

\section{CONCLUSIONS}

We have presented new experimental results of nucleation rates of water vapor in helium in the temperature range of 200-235 K. In this temperature range a transition in the nucleation process is observed at $207 \mathrm{~K}$, which we suggest is due to the change of vapor/liquid to vapor/ice nucleation. A qualitative theoretical explanation of this transition has been given, based on classical nucleation theory. In this theory, the surface energy of ice has a dominant role. Therefore, an expression for the surface energy of ice at these low temperatures was derived, which included one free parameter. This parameter was then fitted to the transition in the nucleation rates. The resulting temperature dependent surface energy has a first order surface phase transition (Cahn transition) at $220 \mathrm{~K}$, which is within the range of experimentally observed temperatures of this surface phase transition. The overall difference in temperature dependency of the nucleation rates of our measurements compared to the measurements of Wölk and Strey $^{2}$ cannot be explained by the influence of onedimensional heat conduction from the end wall in our setup. The differences in the measurements might be explained by the separation of boundary layers, induced by the flows resulting from the expansion. This is the subject of a current investigation. 


\section{ACKNOWLEDGEMENT}

The authors thank Professor F. Peters for providing us with the data of their measurements.

\section{APPENDIX A: PHYSICAL PROPERTIES}

Water

Molar mass (Ref. 18)

$M=0.018015$

Pure component saturated liquid vapor pressure ${ }^{19}$ (originally $T>273 \mathrm{~K}$, however, comparing with Pruppacher ${ }^{12}$ gives $T>223 \mathrm{~K}$ ):

$p_{\text {sat,liquid }}=610.8 \exp [-5.1421 \ln (T / 273.15)$ $-6828.77(1 / T-1 / 273.15)]$

Pure component saturated solid vapor pressure ${ }^{20}$ $(170 \mathrm{~K}<T<250 \mathrm{~K})$

$p_{\text {sat }, \text { solid }}=\exp ((-2663.5 / T+12.537) \ln (10))$

Density of liquid ${ }^{12}(223 \mathrm{~K}<T<273 \mathrm{~K})$ :

$\rho_{\text {liquid }}=999.84+0.086(T-273.15)$ $-0.0108(T-273.15)^{2}$

Density of solid ${ }^{12}(123 \mathrm{~K}<T<273 \mathrm{~K})$ :

$\rho_{\text {solid }}=916.7-0.175(T-273.15)$

$$
-5.0 \times 10^{-4}(T-273.15)^{2}
$$

Liquid/vapor surface tension ${ }^{5}(251 \mathrm{~K}<T<268 \mathrm{~K})$ :

$\sigma_{\text {liquid/vapor }}=0.127245-1.89845 \times 10^{-4} \mathrm{~T}$

Solid/liquid surface tension ${ }^{12}(233 \mathrm{~K}<T<273 \mathrm{~K})$ :

$\sigma_{\text {solid/liquid }}=0.02850+2.5 \times 10^{-4}(T-273.15)$

Latent heat of melting (at $273.15 \mathrm{~K}):^{12}$

$L_{\text {melting }}=6.010 \times 10^{3}$

Latent heat of evaporation (at $373.15 \mathrm{~K}$ ): ${ }^{21}$

$L_{\text {evaporation }}=4.065 \times 10^{4}$

Molar heat of vapor at constant pressure ${ }^{18}$

(temperature range is not given):

$C_{p, \text { vapor }}=32.24+1.924 \times 10^{-3} \mathrm{~T}$

$$
+1.055 \times 10^{-5} T^{2}-3.596 \times 10^{-9} T^{3}
$$

Molar heat of liquid at constant pressure ${ }^{21}$

$(273 \mathrm{~K}<T<373 \mathrm{~K})$ :

$C_{p, \text { liquid }}=717.88-7.626 T+0.03396 T^{2}$

$$
-6.730 \times 10^{-5} T^{3}+5.014 \times 10^{-8} T^{4} \quad\left(\mathrm{~J} \mathrm{~K}^{-1} \mathrm{~mol}^{-1}\right) ;
$$

Molar heat of solid at constant pressure ${ }^{12}$

$(233 \mathrm{~K}<T<273 \mathrm{~K})$ :

$C_{p, \text { solid }}=1.884+0.1320 T$

Difference in entropy between vapor and solid:

$$
\begin{aligned}
\Delta S_{\text {ice } / \text { vapor }}= & S_{\text {vapor }}-S_{\text {ice }} \\
= & S_{\text {ice }}(273.15 \mathrm{~K})+\frac{L_{\text {melting }}}{273.15} \\
& +\int_{273.15}^{373.15} \frac{C_{p, \text { liquid }}}{T} d T \\
& +\frac{L_{\text {evaporation }}}{373.15}+\int_{373.15}^{T} \frac{C_{p, \text { vapor }}}{T} d T \\
& -S_{\text {ice }}(273.15 \mathrm{~K})-\int_{273.15}^{T} \frac{C_{p, \text { solid }}}{T} d T \\
= & 2.943-0.1300 T+0.5275 \times 10^{-5} T^{2} \\
& -0.1199 \times 10^{-8} T^{3}+31.36 \ln (T)
\end{aligned}
$$

Thermal conductivity of helium ${ }^{22}$

(certainly valid for $210 \mathrm{~K}<T<300 \mathrm{~K}$,

probably larger temperature range):

$k_{\mathrm{He}}=-0.02449+0.001124 T-2.929 \times 10^{-6} T^{2}$

$$
+4.493 \times 10^{-9} T^{3}-2.518 \times 10^{-12} T^{4}
$$

$\left(\mathrm{kg} \mathrm{mol}^{-1}\right)$;

(Pa);

$(\mathrm{Pa})$;

$$
\left(\mathrm{kg} \mathrm{m}^{-3}\right)
$$

$\left(\mathrm{kg} \mathrm{m}^{-3}\right)$;

$\left(\mathrm{N} \mathrm{m}^{-1}\right)$

$\left(\mathrm{N} \mathrm{m}^{-1}\right)$;

$\left(\mathrm{J} \mathrm{mol}^{-1}\right)$;

$\left(\mathrm{J} \mathrm{mol}^{-1}\right)$

$\left(\mathrm{J} \mathrm{K}^{-1} ; \mathrm{mol}^{-1}\right)$;

$\left(\mathrm{J} \mathrm{K}^{-1} \mathrm{~mol}^{-1}\right)$;

$\left(\mathrm{J} \mathrm{mol}^{-1}\right)$;

\footnotetext{
ownloaded 19 Jan 2010 to 131.155.151.137. Redistribution
}

APPENDIX B: EXPERIMENTAL DATA

\begin{tabular}{ccccccc}
\hline \hline Run & $p_{0}($ bar $)$ & $T_{0}(\mathrm{~K})$ & $y \times 10^{4}$ & $p($ bar $)$ & $T(\mathrm{~K})$ & $J\left(\mathrm{~m}^{-3} \mathrm{~s}^{-1}\right)$ \\
\hline 425 & 1.678 & 295.75 & 40.20 & 0.9692 & 237.49 & $3.9 \mathrm{E} 15$ \\
429 & 1.719 & 296.65 & 36.58 & 0.9721 & 236.23 & $3.1 \mathrm{e} 14$ \\
430 & 1.738 & 296.65 & 36.66 & 0.9644 & 234.414 & $7.6 \mathrm{E} 15$ \\
432 & 1.758 & 296.55 & 32.10 & 0.9484 & 231.70 & $3.2 \mathrm{E} 15$ \\
433 & 1.778 & 296.45 & 29.65 & 0.9556 & 231.30 & $4.02 \mathrm{E} 14$ \\
434 & 1.799 & 296.55 & 27.58 & 0.9554 & 230.27 & $1.97 \mathrm{E} 14$ \\
435 & 1.819 & 296.45 & 27.66 & 0.9507 & 228.75 & $4.5 \mathrm{E} 15$ \\
436 & 1.838 & 296.55 & 26.72 & 0.9371 & 226.54 & $7.4 \mathrm{e} 16$ \\
437 & 1.859 & 296.55 & 24.96 & 0.9413 & 225.95 & $2.4 \mathrm{E} 16$ \\
438 & 1.878 & 296.55 & 22.72 & 0.9482 & 225.66 & $3.8 \mathrm{E} 15$ \\
439 & 1.938 & 296.45 & 20.35 & 0.9358 & 221.59 & $8.0 \mathrm{E} 16$ \\
440 & 1.978 & 296.35 & 18.90 & 0.9326 & 219.42 & $4.0 \mathrm{E} 17$ \\
442 & 1.978 & 296.65 & 16.49 & 0.9204 & 218.49 & $9.1 \mathrm{E} 16$ \\
444 & 1.999 & 296.65 & 14.87 & 0.9359 & 219.05 & $4.3 \mathrm{E} 15$ \\
448 & 2.099 & 296.45 & 11.24 & 0.9316 & 214.24 & $3.2 \mathrm{E} 16$ \\
450 & 2.099 & 296.15 & 11.58 & 0.9741 & 217.90 & $8.2 \mathrm{E} 14$ \\
451 & 2.099 & 296.15 & 11.70 & 0.9386 & 214.70 & $4.1 \mathrm{E} 16$ \\
452 & 2.099 & 296.15 & 11.54 & 0.9553 & 216.22 & $3.9 \mathrm{E} 15$ \\
455 & 2.113 & 295.95 & 10.23 & 0.9213 & 212.37 & $1.1 \mathrm{E} 17$ \\
469 & 2.303 & 295.25 & 6.425 & 0.9725 & 209.19 & $2.0 \mathrm{E} 15$ \\
470 & 2.303 & 295.35 & 6.649 & 0.9605 & 208.22 & $1.7 \mathrm{E} 16$ \\
471 & 2.303 & 295.45 & 6.455 & 0.9583 & 208.10 & $2.2 \mathrm{E} 16$ \\
477 & 2.503 & 294.85 & 2.872 & 1.005 & 204.74 & $9.1 \mathrm{E} 15$ \\
480 & 2.503 & 295.15 & 2.612 & 0.9855 & 203.34 & $1.6 \mathrm{E} 16$ \\
482 & 2.518 & 295.45 & 2.391 & 0.9685 & 201.66 & $3.0 \mathrm{E} 16$ \\
484 & 2.343 & 295.65 & 4.584 & 0.9554 & 206.85 & $9.1 \mathrm{E} 16$ \\
486 & 2.343 & 295.45 & 4.093 & 0.9580 & 206.65 & $4.4 \mathrm{E} 16$ \\
487 & 2.383 & 295.55 & 3.434 & 0.9629 & 205.75 & $1.4 \mathrm{E} 16$ \\
491 & 2.108 & 295.65 & 14.33 & 0.9851 & 218.14 & $1.2 \mathrm{E} 16$ \\
493 & 2.048 & 295.75 & 17.19 & 0.9817 & 220.42 & $1.6 \mathrm{E} 16$ \\
494 & 1.999 & 295.85 & 19.86 & 0.9809 & 222.60 & $1.2 \mathrm{E} 16$ \\
496 & 2.192 & 294.45 & 9.723 & 0.9721 & 212.73 & $5.0 \mathrm{E} 16$ \\
498 & 1.737 & 295.45 & 40.19 & 1.008 & 237.67 & $2.2 \mathrm{E} 15$ \\
499 & 1.798 & 294.85 & 30.81 & 0.9994 & 233.15 & $1.7 \mathrm{E} 14$ \\
500 & 1.838 & 295.05 & 30.77 & 0.9968 & 231.06 & $3.3 \mathrm{E} 15$ \\
505 & 5.054 & 295.25 & 1.974 & 2.1135 & 208.37 & $1.5 \mathrm{E} 16$ \\
\hline \hline & & & & & &
\end{tabular}

${ }^{1}$ P. Peeters, J. Hrubý, and M. E. H. van Dongen, J. Phys. Chem. B 105, 11763 (2001).

${ }^{2}$ J. Wölk and R. Strey, J. Phys. Chem. B 105, 11683 (2001).

${ }^{3}$ F. Peters and B. Paikert, Exp. Fluids 7, 521 (1989).

${ }^{4}$ C. C. M. Luijten, P. Peeters, and M. E. H. van Dongen, J. Chem. Phys. 111, 8535 (1999).

${ }^{5}$ C. C. M. Luijten and M. E. H. van Dongen, J. Chem. Phys. 111, 8524 (1999).

${ }^{6}$ D. Kashchiev, Nucleation: Basic Theory with Applications (ButterworthHeinemann, Oxford, 2000).

${ }^{7}$ J. G. Dash, Fu Haiying, and J. S. Wettlaufer, Rep. Prog. Phys. 58, 115 (1995).

${ }^{8}$ A. Döppenschmidt and H.-J. Butt, Langmuir 16, 6709 (2000).

${ }^{9}$ X. Wei, P. B. Miranda, and Y. R. Shen, Phys. Rev. Lett. 86, 1554 (2001).

${ }^{10}$ G. N. J. Antonow, J. Chim. Phys. Phys.-Chim. Biol. 5, 372 (1907).

${ }^{11}$ J. S. Rowlinson and B. Widom, Molecular Theory of Capillarity (Clarendon, Oxford, 1982).

${ }^{12} \mathrm{H}$. R. Pruppacher and J. D. Klett, Microphysics of Clouds and Precipitation (Reidel, Dordrecht, 1978).

${ }^{13}$ K. N. H. Looijmans and M. E. H. van Dongen, Exp. Fluids 237, 54 (1997).

${ }^{14}$ K. N. H. Looijmans, P. C. Kriesels, and M. E. H. van Dongen, Exp. Fluids 15, 61 (1993).

${ }^{15}$ J. W. Cahn, J. Chem. Phys. 66, 3667 (1977).

${ }^{16}$ J. C. Keck, Lett. Heat Mass Transfer 8, 313 (1981).

${ }^{17}$ M. E. H. van Dongen, Ph.D. thesis, "Thermal diffusion effects in shock 
tube boundary layers," Eindhoven University of Technology, Eindhoven, 1978.

${ }^{18}$ R. C. Reid, J. M. Prausnitz, and B. E. Poling, The Properties of Gases and Liquids (McGraw-Hill, New York, 1987).

${ }^{19}$ N. B. Vargaftik, Tables on the Thermophysical Properties of Liquids and Gases, 2nd ed. (Hemisphere, London, 1975).
${ }^{20}$ J. Marti and K. Mauersberger, Geophys. Res. Lett. 20, 363 (1993).

${ }^{21}$ NIST Chemistry WebBook, NIST Standard Reference Database Number 69, July 2001, edited by P.J. Linstrom and W.G. Mallard, http:// webbook.nist.gov

${ }^{22}$ C.-H. Hung, M. Krasnopoler, and J. L. Katz, J. Chem. Phys. 90, 1856 (1989). 